\title{
MENINGKATKAN KETERAMPILAN DALAM PROMOSI MELALUI PELATIHAN BAHASA INGGRIS UNTUK MEMPERSIAPKAN DESA EKOWISATA PANCOH DI RANAH INTERNASIONAL
}

\author{
Dyah Ayu Musyrifah', Tia Atika Putri' ${ }^{1}$ Ayu Sarah ${ }^{3}$, Rindah Nurjanah $^{4}$ \\ 1,2Prodi Teknik Industri, Fakultas Teknologi Industri, Universitas Islam Indonesia \\ ${ }^{3,4}$ Prodi Pendidikan Bahasa Inggris, Fakultas Psikologi dan IImu Sosial Budaya, \\ Universitas Islam Indonesia \\ Yogyakarta
}

\begin{abstract}
ABSTRAK
Daerah Istimewa Yogyakarta (DIY) dikenal dengan keanekaragaman alam dan budayanya. Desa Pancoh dikenal sebagai salah satu tempat wisata di Kabupaten Sleman dari 132 tempat wisata yang ada di DIY. Promosi yang dilakukan Desa Pancoh yaitu melalui media sosial dan brosur. Perlu adanya peningkatan keterampilan dalam melakukan promosi salah satunya dengan mengadakan pelatihan bahasa Inggris tentang menulis dan berbicara. IM TELLING adalah program bahasa Inggris yang dirancang khusus untuk meningkatkan kemampuan berbahasa Inggris masyarakat Pancoh. Metode yang digunakan dalam program ini adalah awareness raising, active learning dan promotion skill through social media. Keberhasilan program diukur melalui pre test dan post test berdasarkan describing photo or pictures tricks (British Council, 2004). Terdapat 7 rubrik dengan skor 1-5 dimana pada hasil pre test yaitu sebesar 2.14;1.14;1.5;1.21;1.86;1.29;1.07. Sedangkan pada post test mengalami kenaikan dengan masing-masing skor sebesar 2.86;2.64;2.93;2.79;3.14;2.93;1.93. Hasil dari Program ini diharapkan dapat membantu Desa Ekowisata Pancoh untuk lebih dikenal di ranah internasional.
\end{abstract}

Kata kunci: active learning, awareness raising, desa ekowisata pancoh, keterampilan promosi, promotion skill

\section{PENDAHULUAN}

Provinsi Daerah Istimewa Yogyakarta (DIY) terkenal dengan pusat kebudayaan dan kekayaan alamnya, tak heran apabila kota ini menjadi tujuan wisata baik wisatawan lokal maupun mancanegara. Berikut adalah grafik peningkatan wisatawan mancanegara yang berkunjung ke Provinsi DIY terhitung dari tahun 2012-2016.

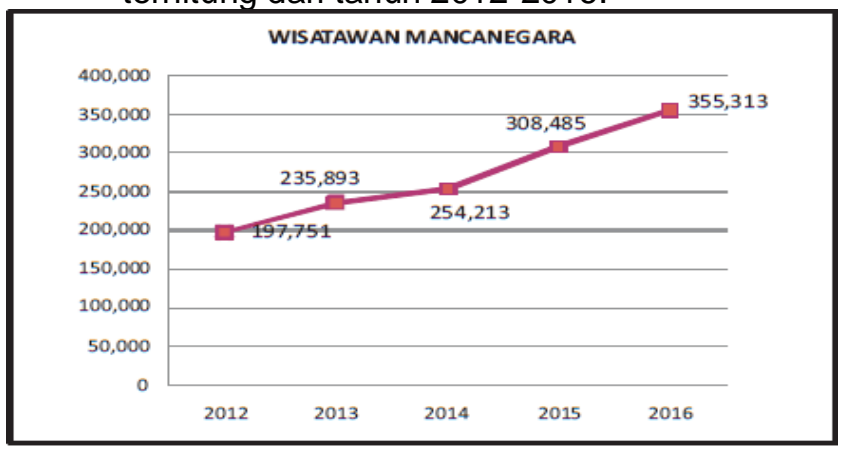

Gambar 1. Grafik Jumlah Wisatawan Mancanegara yang Berkunjung ke Kota Yogyakarta (Sumber: Dinas Pariwisata

Daerah Istimewa Yogyakarta Data

Statistik Kepariwisataan DIY 2016) Berdasarkan data tersebut,
diketahui bahwa wisatawan mancanegara yang berkunjung ke Provinsi DIY mengalami peningkatan setiap tahunnya dalam kurun waktu lima tahun terakhir, yang mana puncaknya pada tahun 2016 sebanyak 355.313 wisatawan mancanegara memilih Provinsi DIY sebagai destinasi wisata. Peningkatan jumlah wisatawan mancanegara tersebut harus diimbangi dengan skill berbahasa Inggris yang baik, mengingat rata-rata wisatawan yang datang menggunakan bahasa Inggris untuk berkomunikasi dengan masyarakat lokal. Sementara itu, 
Indonesia berada di posisi 32 dari 72 negara di dunia dengan skor english proficiency index sebesar 52,94 sehingga kemampuan bahasa Inggris masyarakat Indonesia masih dalam taraf menengah (www.ef.com/epi/).

Desa Ekowisata Pancoh yang terletak di Kabupaten Sleman merupakan salah satu desa wisata yang cukup sering dikunjungi oleh wisatawan lokal. Desa ini menawarkan beberapa paket untuk live in dengan kehidupan khas masyarakat di pedesaan. Hingga tahun 2017, belum terdapat wisatawan mancanegara yang melakukan live in di Desa ini. Kurangnya promosi serta lemahnya skill berbahasa Inggris masyarakat nya adalah penyebab Desa Ekowisata Pancoh belum bisa menarik wisatawan mancanegara untuk menjadikan desa ini sebagai destinasi wisata.

Dari latar belakang tersebut, penulis menyusun sebuah program untuk meningkatkan skill berbahasa Inggris melalui pelatihan serta mengajarkan kegiatan promosi yang baik dan benar kepada masyarakat Desa Ekowisata Pancoh.

\section{METODE}

Metode pelaksanaan dalam kegiatan ini berupa awareness raising, active learning dan promotion skill through social media. Metode awareness raising ditujukan untuk meningkatkan kesadaran masyarakat akan pentingnya ilmu pengetahuan dan keterampilan berbahasa Inggris melalui kegiatan english training. Metode selanjutnya adalah active learning yang merupakan kegiatan belajar mengajar yang melibatkan intelektual dan emosional siswa sehingga dapat berperan dan berpartisipasi aktif dalam melakukan kegiatan belajar, dengan tujuan agar pembelajaran dapat diserap dan diaplikasikan secara efektif dalam kehidupan sehari-hari (Hosnan, 2014). Metode terakhir adalah promotion skill through social media yang merupakan sarana untuk meningkatkan keterampilan masyarakat dalam mempromosikan desa ekowisata guna memajukan perekonomian masyarakat di desa tersebut.

\section{Awareness Raising}

Metode ini dilakukan dengan cara sosialisasi untuk memberikan arahan dan pengetahuan mengenai program english training serta langkah-langkah dalam melakukan kegiatan promosi.

\section{Active Learning}

Metode ini sangat penting untuk pembekalan masyarakat desa ekowisata yang sedang berkembang. Metode active learning yang digunakan memungkinkan masyarakat untuk aktif mempraktikkan bahasa Inggris yang telah dipelajari dengan kontinuitas. Adapun komponen pembelajaran yang terdapat dalam metode active learning sebagai berikut:

a. Fun Speaking

Fun speaking adalah aktivitas berbicara menggunakan bahasa Inggris yang dikemas dengan efektif dan menyenangkan. Output dari kegiatan ini adalah masyarakat dapat mendeskripsikan tempat, mempraktikkan daily conversation serta guiding tourist. Keterampilan tersebut ditambahkan dengan teknik persuasif yang akan menunjang teknik promosi.

\section{b. Persuasive Writing}

Persuasive writing adalah keterampilan dalam teknik menulis dengan ragam bahasa yang mudah dipahami dan persuasif sehingga dapat menunjang kegiatan promosi. Persuasive writing menjadi teknik pembelajaran yang sangat baik untuk mengembangkan writing skill dan promotion skill.

c. Pantomime (Pancoh Ecotourism's Monopoly Game)

Pantomime adalah permainan monopoli yang berisi tempat-tempat wisata yang ada di Desa Ekowisata Pancoh. Permainan ini bertujuan untuk mengasah kreativitas masyarakat dalam mendeskripsikan tempat-tempat wisata yang ada di sekitarnya.

d. Oh Trap (Pancoh Future Plan)

Oh Trap adalah permainan yang berupa penyampaian keinginan dan harapan untuk Desa Ekowisata Pancoh di masa depan dalam range waktu yang berurutan.

e. Reply (Role Play) Game

Reply game adalah permainan seni peran dimana peserta akan berperan 
sebagai tokoh dalam sebuah cerita atau melakukan simulasi dari sebuah peristiwa. Peristiwa yang akan diangkat adalah seputar how to guide well.

3. Promotion Skill through Social Media Promotion skill through social media adalah kegiatan saling bertukar ilmu dengan masyarakat dan melatih masyarakat Desa Ekowisata Pancoh melalui media brosur dan media sosial seperti instagram. Beberapa aktivitas dari kegiatan ini adalah memberikan pengetahuan bagaimana menyeleksi gambar, memotret obyek, membuat caption yang menarik untuk netizen serta mengoptimalkan pengelolaan akun instagram dengan baik untuk kegiatan promosi.

\section{HASIL}

Pada program IM TELLING terdapat 7 partisipan atau siswa yang aktif mengikuti kegiatan. Siswa terdiri dari kalangan SMP hingga kuliah.
Kegiatan belajar dilakukan setiap dua kali seminggu dengan total sebanyak sepuluh kali pertemuan. Setiap siswa diwajibkan untuk melakukan pre test dan post test untuk mengetahui peningkatan setelah mengikuti program. Penilaian keberhasilan dalam melaksanakan program IM TELLING yaitu berdasarkan pada 7 rubrik yang ada pada Describing Photo or Pictures Tricks (Council, 2004). Rubrik yang dinilai yaitu:

1. Preparation

2. Time Management

3. Confidence

4. Fluency

5. Description "what is in the picture"

6. Description of what's happening

7. Dealing with unclear information Masing-masing rubrik memiliki skor 1-5 dengan nilai semakin tinggi maka semakin baik. Berikut tabel penilaian tiap rubrik:

Tabel 1. Rubrik Penilaian Mendeskripsikan Gambar

\begin{tabular}{|c|c|c|c|c|c|c|}
\hline No & Terms & $\begin{array}{c}1 \\
\text { (Poor) }\end{array}$ & $\begin{array}{c}2 \\
\text { (Less) }\end{array}$ & $\begin{array}{c}3 \\
\text { (Sufficient) }\end{array}$ & $\begin{array}{c}4 \\
(G o o d)\end{array}$ & $\begin{array}{c}5 \\
\text { (Very Good) }\end{array}$ \\
\hline 1 & Preparation & $\begin{array}{l}\text { Ss show no } \\
\text { interest to } \\
\text { think before } \\
\text { starting } \\
\text { talking }\end{array}$ & $\begin{array}{l}\text { Ss look at } \\
\text { the picture } \\
\text { but it does } \\
\text { not } \\
\text { contribute } \\
\text { to the } \\
\text { describing } \\
\text { process }\end{array}$ & $\begin{array}{l}\text { Ss look at } \\
\text { the picture } \\
\text { and take a } \\
\text { few } \\
\text { moments to } \\
\text { think before } \\
\text { starting } \\
\text { talking }\end{array}$ & $\begin{array}{l}\text { Ss look at } \\
\text { the picture } \\
\text { somewhat } \\
\text { carefully } \\
\text { and take a } \\
\text { few } \\
\text { moments to } \\
\text { think before } \\
\text { starting } \\
\text { talking }\end{array}$ & $\begin{array}{l}\text { Ss look at } \\
\text { the picture } \\
\text { carefully } \\
\text { and take a } \\
\text { few } \\
\text { moments to } \\
\text { think before } \\
\text { starting } \\
\text { talking }\end{array}$ \\
\hline 2 & $\begin{array}{l}\text { Time } \\
\text { Management }\end{array}$ & $\begin{array}{l}\text { Ss can } \\
\text { describe the } \\
\text { pictures at } \\
\text { least one } \\
\text { sentences } \\
\text { every } \\
\text { minute } \\
\text { without any } \\
\text { prompts }\end{array}$ & $\begin{array}{l}\text { Ss can } \\
\text { describe the } \\
\text { pictures at } \\
\text { least two } \\
\text { sentences } \\
\text { every } \\
\text { minute } \\
\text { without any } \\
\text { prompts }\end{array}$ & $\begin{array}{l}\text { Ss can } \\
\text { describe the } \\
\text { pictures at } \\
\text { least three } \\
\text { sentences } \\
\text { every } \\
\text { minute } \\
\text { without any } \\
\text { prompts }\end{array}$ & $\begin{array}{l}\text { Ss can } \\
\text { describe the } \\
\text { pictures at } \\
\text { least four } \\
\text { sentences } \\
\text { every } \\
\text { minute } \\
\text { without any } \\
\text { prompts }\end{array}$ & $\begin{array}{l}\text { Ss can } \\
\text { describe the } \\
\text { pictures at } \\
\text { least five } \\
\text { sentences } \\
\text { every } \\
\text { minute } \\
\text { without any } \\
\text { prompts }\end{array}$ \\
\hline 3 & Confidence & $\begin{array}{l}\text { Ss give up } \\
\text { when s/he } \\
\text { doesn't } \\
\text { know the } \\
\text { words for all } \\
\text { the things in } \\
\text { the picture. } \\
\text { S/he is able } \\
\text { to describe } \\
\text { the related }\end{array}$ & $\begin{array}{l}\text { Ss panic } \\
\text { when s/he } \\
\text { doesn't } \\
\text { know the } \\
\text { words for all } \\
\text { the things in } \\
\text { the picture. } \\
\text { S/he is able } \\
\text { to describe } \\
\text { the related }\end{array}$ & $\begin{array}{l}\text { Ss } \\
\text { somewhat } \\
\text { panic when } \\
\text { s/he doesn't } \\
\text { know the } \\
\text { words for all } \\
\text { the things in } \\
\text { the picture. } \\
\text { S/he is able } \\
\text { to describe }\end{array}$ & $\begin{array}{l}\text { Ss } \\
\text { somewhat } \\
\text { do not panic } \\
\text { when s/he } \\
\text { doesn't } \\
\text { know the } \\
\text { words for all } \\
\text { the things in } \\
\text { the picture. } \\
\text { S/he is able }\end{array}$ & $\begin{array}{l}\text { Ss do not } \\
\text { panic when } \\
\text { s/he doesn't } \\
\text { know the } \\
\text { words for all } \\
\text { the things in } \\
\text { the picture. } \\
\text { S/he is able } \\
\text { to describe } \\
\text { the related }\end{array}$ \\
\hline
\end{tabular}




\begin{tabular}{|c|c|c|c|c|c|c|}
\hline No & Terms & $\begin{array}{c}1 \\
\text { (Poor) }\end{array}$ & $\begin{array}{c}2 \\
(L e s s)\end{array}$ & $\begin{array}{c}3 \\
\text { (Sufficient) }\end{array}$ & $\begin{array}{c}4 \\
(\text { Good) }\end{array}$ & $\begin{array}{c}5 \\
\text { (Very Good) }\end{array}$ \\
\hline & & synonym. & synonym. & $\begin{array}{l}\text { the related } \\
\text { synonym. }\end{array}$ & $\begin{array}{l}\text { to describe } \\
\text { the related } \\
\text { synonym. }\end{array}$ & synonym. \\
\hline 4 & Fluency & $\begin{array}{l}\text { Ss are able } \\
\text { to perform } \\
\text { the } \\
\text { description } \\
\text { with fillers } \\
\text { and no } \\
\text { impressive } \\
\text { manners. }\end{array}$ & $\begin{array}{l}\text { Ss are able } \\
\text { to perform } \\
\text { the } \\
\text { description } \\
\text { with fillers } \\
\text { and less } \\
\text { impressive } \\
\text { manners. }\end{array}$ & $\begin{array}{l}\text { Ss are able } \\
\text { to perform } \\
\text { the } \\
\text { description } \\
\text { with some } \\
\text { fillers and } \\
\text { less } \\
\text { impressive } \\
\text { manners. }\end{array}$ & $\begin{array}{l}\text { Ss are able } \\
\text { to perform } \\
\text { the } \\
\text { description } \\
\text { with some } \\
\text { fillers and } \\
\text { impressive } \\
\text { manners. }\end{array}$ & $\begin{array}{l}\text { Ss are able } \\
\text { to perform } \\
\text { the } \\
\text { description } \\
\text { without any } \\
\text { significant } \\
\text { fillers and } \\
\text { impressive } \\
\text { manners. }\end{array}$ \\
\hline 5 & $\begin{array}{l}\text { Description } \\
\text { "What is in } \\
\text { the picture?" }\end{array}$ & $\begin{array}{l}\text { Ss are } \\
\text { unable to } \\
\text { use simple } \\
\text { present } \\
\text { tense, and } \\
\text { never } \\
\text { employ } \\
\text { some } \\
\text { expressions } \\
\text { (I can see, } \\
\text { there's/are) } \\
\text { and correct } \\
\text { adverbials } \\
\text { with many } \\
\text { significant } \\
\text { errors. }\end{array}$ & $\begin{array}{l}\text { Ss are able } \\
\text { to use } \\
\text { simple } \\
\text { present } \\
\text { tense, but } \\
\text { less } \\
\text { employing } \\
\text { some } \\
\text { expressions } \\
\text { (I can see, } \\
\text { there's/are) } \\
\text { and correct } \\
\text { adverbials } \\
\text { with some } \\
\text { errors. }\end{array}$ & $\begin{array}{l}\text { Ss is able to } \\
\text { use simple } \\
\text { present } \\
\text { tense, and } \\
\text { employ } \\
\text { some } \\
\text { expressions } \\
\text { (I can see, } \\
\text { there's/are) } \\
\text { and correct } \\
\text { adverbials } \\
\text { without } \\
\text { some } \\
\text { errors. }\end{array}$ & $\begin{array}{l}\text { Ss is able to } \\
\text { use simple } \\
\text { present } \\
\text { tense, and } \\
\text { employ } \\
\text { some } \\
\text { expressions } \\
\text { (I can see, } \\
\text { there's/are) } \\
\text { and correct } \\
\text { adverbials } \\
\text { without any } \\
\text { significant } \\
\text { errors. }\end{array}$ & $\begin{array}{l}\text { Ss are able } \\
\text { to use } \\
\text { simple } \\
\text { present } \\
\text { tense, } \\
\text { compound } \\
\text { sentence, } \\
\text { and employ } \\
\text { large types } \\
\text { of } \\
\text { expressions } \\
\text { (I can see, } \\
\text { there's/are) } \\
\text { and correct } \\
\text { adverbials } \\
\text { without any } \\
\text { significant } \\
\text { errors. }\end{array}$ \\
\hline 6 & $\begin{array}{l}\text { Description } \\
\text { of what's } \\
\text { happening }\end{array}$ & $\begin{array}{l}\text { Ss are } \\
\text { unable to } \\
\text { employ } \\
\text { present } \\
\text { continuous } \\
\text { tense }(V- \\
\text { ing) and } \\
\text { have many } \\
\text { significant } \\
\text { errors }\end{array}$ & $\begin{array}{l}\text { Ss are able } \\
\text { to employ } \\
\text { present } \\
\text { continuous } \\
\text { tense ( } V \text { - } \\
\text { ing) but with } \\
\text { many } \\
\text { significant } \\
\text { errors }\end{array}$ & $\begin{array}{l}\text { Ss are able } \\
\text { to employ } \\
\text { present } \\
\text { continuous } \\
\text { tense }(V- \\
\text { ing) with } \\
\text { some } \\
\text { significant } \\
\text { errors }\end{array}$ & $\begin{array}{l}\text { Ss are able } \\
\text { to employ } \\
\text { present } \\
\text { continuous } \\
\text { tense }(V- \\
\text { ing) with } \\
\text { little } \\
\text { significant } \\
\text { errors }\end{array}$ & $\begin{array}{l}\text { Ss are able } \\
\text { to employ } \\
\text { present } \\
\text { continuous } \\
\text { tense and } \\
\text { compound } \\
\text { sentence } \\
\text { (V-ing) } \\
\text { without any } \\
\text { significant } \\
\text { errors }\end{array}$ \\
\hline 7 & $\begin{array}{l}\text { Dealing with } \\
\text { unclear } \\
\text { information }\end{array}$ & $\begin{array}{l}\text { Ss are } \\
\text { unable to } \\
\text { employ } \\
\text { certain } \\
\text { expressions } \\
\text { related to } \\
\text { 8uncertainty } \\
\text { (looks, } \\
\text { might, could } \\
\text { be, maybe) } \\
\text { although } \\
\text { equipped } \\
\text { with } \\
\text { prompts }\end{array}$ & $\begin{array}{l}\text { Ss are able } \\
\text { to employ } \\
\text { certain } \\
\text { expressions } \\
\text { related to } \\
\text { 8uncertainty } \\
\text { (looks, } \\
\text { might, could } \\
\text { be, maybe) } \\
\text { with a lot of } \\
\text { prompts }\end{array}$ & $\begin{array}{l}\text { Ss are able } \\
\text { to employ } \\
\text { certain } \\
\text { expressions } \\
\text { related to } \\
\text { 8uncertainty } \\
\text { (looks, } \\
\text { might, could } \\
\text { be, maybe) } \\
\text { with some } \\
\text { prompts }\end{array}$ & $\begin{array}{l}\text { Ss are able } \\
\text { to employ } \\
\text { certain } \\
\text { expressions } \\
\text { related to } \\
\text { 8uncertainty } \\
\text { (looks, } \\
\text { might, could } \\
\text { be, maybe) } \\
\text { with little } \\
\text { prompts }\end{array}$ & $\begin{array}{l}\text { Ss are able } \\
\text { to employ } \\
\text { certain } \\
\text { expressions } \\
\text { related to } \\
\text { 8uncertainty } \\
\text { (looks, } \\
\text { might, could } \\
\text { be, maybe) } \\
\text { without any } \\
\text { prompts }\end{array}$ \\
\hline
\end{tabular}


Pre test dan post test dilakukan dengan mendiskripsikan gambar yang tidak asing bagi siswa. Berikut hasil pre test dan post test dari setiap siswa:

Tabel 2. Hasil Pre Test

\begin{tabular}{|c|c|c|c|c|c|c|c|}
\hline Nama & Preparation & $\begin{array}{c}\text { Time } \\
\text { Management }\end{array}$ & Confidence & Fluency & $\begin{array}{l}\text { Description } \\
\text { "what is in } \\
\text { the picture" }\end{array}$ & $\begin{array}{c}\text { Description of } \\
\text { what's } \\
\text { happening }\end{array}$ & $\begin{array}{l}\text { Dealing with } \\
\text { unclear } \\
\text { information }\end{array}$ \\
\hline ANA & 2 & 1.5 & 2 & 2 & 2.5 & 2 & 1.5 \\
\hline DIAN & 2 & 1 & 2 & 1.5 & 1.5 & 1.5 & 1 \\
\hline ERINA & 2 & 1 & 1.5 & 1 & 2 & 1 & 1 \\
\hline FATMA & 2 & 1 & 1.5 & 1 & 1.5 & 1 & 1 \\
\hline IMAM & 3 & 1 & 1 & 1 & 2 & 1 & 1 \\
\hline MELANI & 2 & 1.5 & 1.5 & 1 & 2 & 1.5 & 1 \\
\hline WENDY & 2 & 1 & 1 & 1 & 1.5 & 1 & 1 \\
\hline
\end{tabular}

Tabel 3. Hasil Post Test

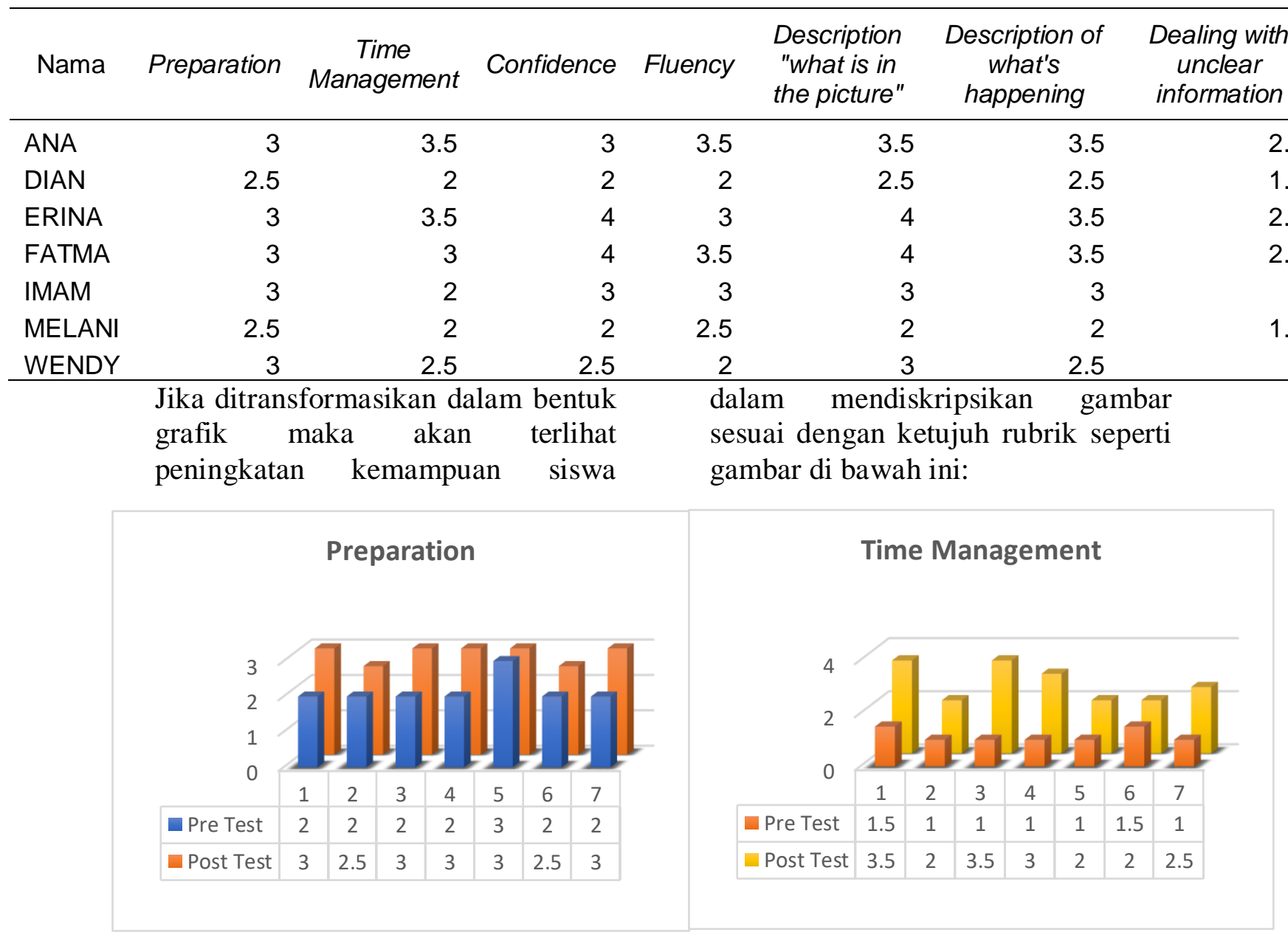

Gambar 2. Hasil Preparation

Gambar 3. Hasil Time Management 


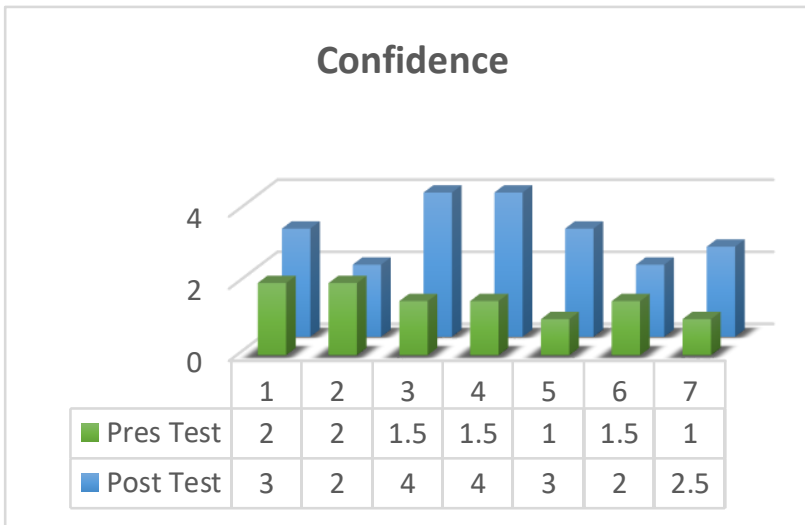

Gambar 4. Hasil Confidence

\section{Description of what's happening}

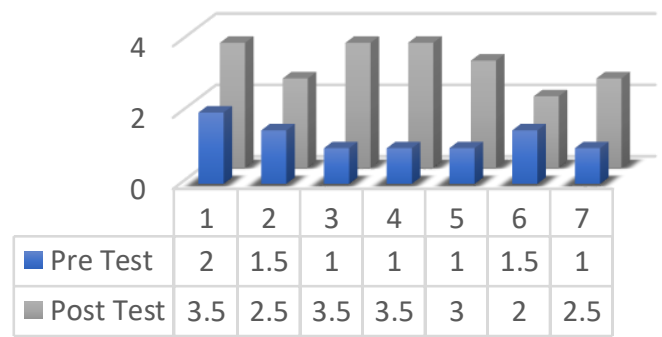

Gambar 7. Description of what's Happening

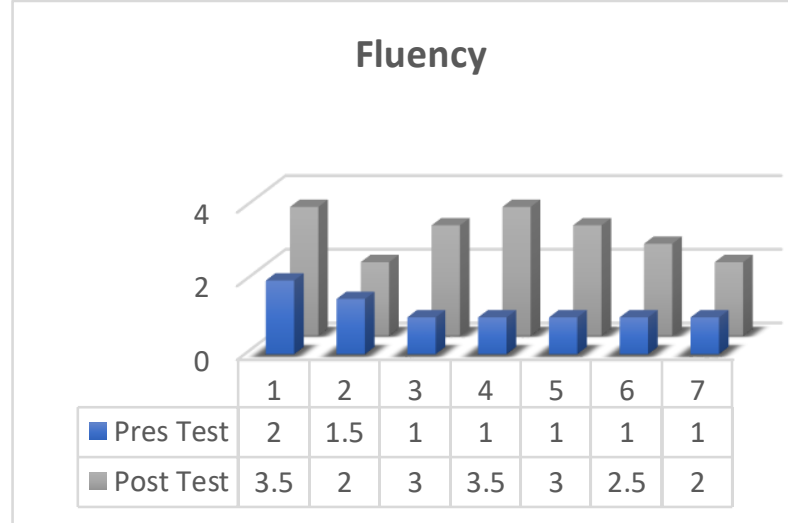

Gambar 5. Hasil Fluency

Description "what is in the picture"

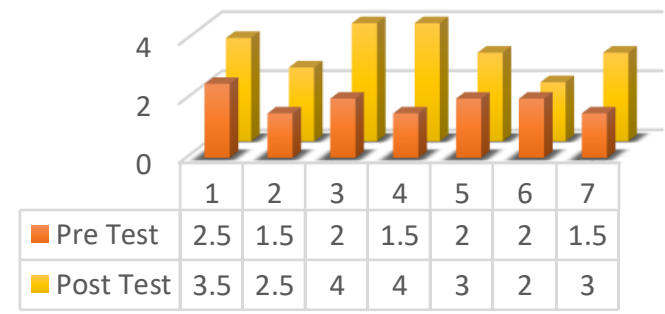

Dealing with unclear information

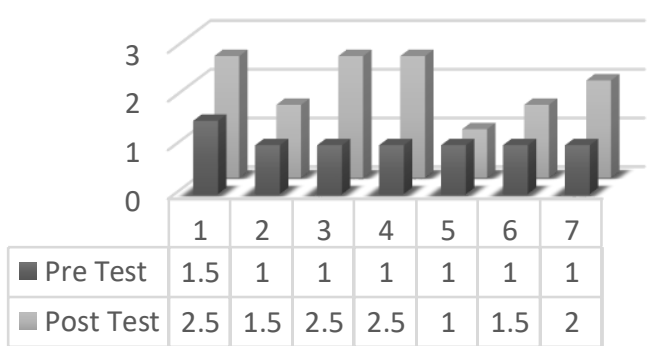

Gambar 8. Dealing with Unclear Information

Gambar 6. Description "What is in the Picture?"

Pada gambar 2 sampai 8 terlihat bahwa terjadi kenaikan dari skor pre test. Nilai pre test dan post test tersebut didapatkan dari rata-rata setiap rubrik dari tabel 2 dan 3. Hasil tersebut dijadikan penilaian pada kemampuan bahasa inggris siswa. Terlihat bahwa kemampuan siswa masih kurang berdasarkan rata-rata yang didapatkan namun mengalami peningkatan yang belum signifikan setelah mengikuti program. 


\section{KESIMPULAN DAN SARAN}

Berdasarkan hasil dari penelitian ini peningkatan kemampuan bahasa inggris masyarakat Desa Ekowisata Pancoh belum signifikan. Pada pelaksanan program IM TELLING usia tidak mempengaruhi kemahiran dalam berbahasa inggris, oleh karena itu usia diabaikan. Kemampuan bahasa inggris remaja Desa Ekowisata Pancoh terbilang masih kurang. Rata-rata skor pada pre test yaitu sebesar 2.14; 1.14; $1.5 ; 1.21 ; 1.86 ; 1.29 ; 1.07$. Sedangkan pada post test mengalami kenaikan dengan masing-masing skor sebesar 2.86; 2.64; 2.93; 2.79; 3.14; 2.93; 1.93. Adapun saran untuk penelitian selanjutnya yaitu dengan melaksanakan kegiatan belajar dengan rentang waktu yang lebih lama serta menerapkan metode mengajar yang menarik agar kemampuan bahasa inggris dapat meningkat lebih signifikan.

\section{DAFTAR PUSTAKA}

Council, B. (2004). Describe a photo or picture. Retrieved from British Council: britishcouncil.org

EPI, E. (2018, Juni). Indeks Kecakapan Berbahasa Inggris EF Indonesia. Retrieved from Indeks Kecakapan Berbahasa Inggris EF: https://www.ef.co.id/epi/regions/ asia/indonesia/

Yogyakarta, D. P. (2017, Mei). Statistik Pariwisata DIY 2016. Retrieved from Visiting Jogja: https://visitingjogja.com/ 